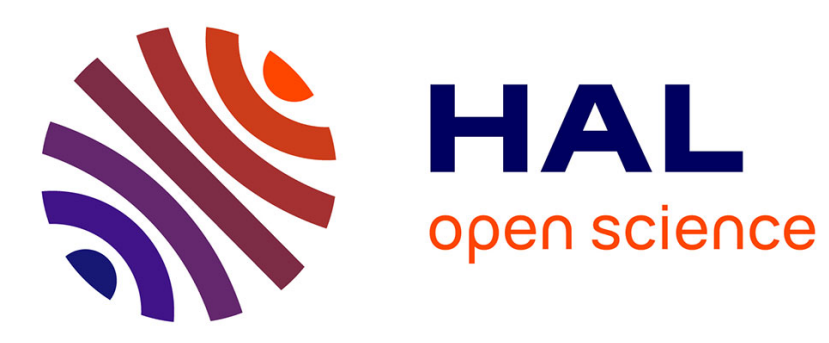

\title{
Individual and combined effects of subclinical doses of deoxynivalenol and fumonisins in piglets
}

\author{
Bertrand Grenier, Ana-Paula Loureiro-Bracarense, Joelma Lucioli, Graziela \\ Drociunas Pacheco, Anne Marie Cossalter, Wulf-Dieter Moll, Gerd \\ Schatzmayr, Isabelle P. Oswald
}

\section{To cite this version:}

Bertrand Grenier, Ana-Paula Loureiro-Bracarense, Joelma Lucioli, Graziela Drociunas Pacheco, Anne Marie Cossalter, et al.. Individual and combined effects of subclinical doses of deoxynivalenol and fumonisins in piglets. Molecular Nutrition and Food Research, 2011, 55, pp.761-771. 10.1002/mnfr.201000402 . hal-02644751

\section{HAL Id: hal-02644751 \\ https://hal.inrae.fr/hal-02644751}

Submitted on 28 May 2020

HAL is a multi-disciplinary open access archive for the deposit and dissemination of scientific research documents, whether they are published or not. The documents may come from teaching and research institutions in France or abroad, or from public or private research centers.
L'archive ouverte pluridisciplinaire HAL, est destinée au dépôt et à la diffusion de documents scientifiques de niveau recherche, publiés ou non, émanant des établissements d'enseignement et de recherche français ou étrangers, des laboratoires publics ou privés. 


\title{
Individual and combined effects of subclinical doses of deoxynivalenol and fumonisins in piglets
}

\author{
Bertrand Grenier ${ }^{1,2}$, Ana-Paula Loureiro-Bracarense ${ }^{3}$, Joelma Lucioli ${ }^{3}$, \\ Graziela Drociunas Pacheco ${ }^{1,3}$, Anne-Marie Cossalter ${ }^{1}$, Wulf-Dieter Moll ${ }^{2}$, Gerd Schatzmayr ${ }^{2}$ \\ and Isabelle P. Oswald ${ }^{1}$
}

${ }^{1}$ INRA, Unité de Pharmacologie-Toxicologie, Toulouse, France

${ }^{2}$ BIOMIN Research Center, Tulln, Austria

${ }^{3}$ Universidade Estadual de Londrina, Lab Patologia Animal, Londrina, Brazil

Scope: Deoxynivalenol (DON) and fumonisins (FB) are the most frequently encountered mycotoxins produced by Fusarium species and most commonly co-occur in animal diets. These mycotoxins were studied for their toxicity in piglets on several parameters including plasma biochemistry, organ histopathology and immune response.

Methods and results: Twenty-four 5-wk-old animals were randomly assigned to four different groups, receiving separate diets for $5 \mathrm{wk}$, a control diet, a diet contaminated with either DON $(3 \mathrm{mg} / \mathrm{kg})$ or FB $(6 \mathrm{mg} / \mathrm{kg})$ or both toxins. At days 4 and 16 of the trial, the animals were subcutaneously immunized with ovalbumin to assess their specific immune response. The different diets did not affect animal performance and had minimal effect on hematological and biochemical blood parameters. By contrast, DON and FB induced histopathological lesions in the liver, the lungs and the kidneys of exposed animals. The liver was significantly more affected when the two mycotoxins were present simultaneously. The contaminated diets also altered the specific immune response upon vaccination as measured by reduced anti-ovalbumin IgG level in the plasma and reduced lymphocyte proliferation upon antigenic stimulation. Because cytokines play a key role in immunity, the expression levels of IL-8, IL$1 \beta$, IL- 6 and macrophage inflammatory protein- $1 \beta$ were measured by RT-PCR at the end of the experiment. The expression of these four cytokines was significantly decreased in the spleen of piglets exposed to multi-contaminated diet.

Conclusion: Taken together, our data indicate that ingestion of multi-contaminated diet induces greater histopathological lesions and higher immune suppression than ingestion of mono-contaminated diets.

\section{Keywords:}

Co-contamination / Deoxynivalenol / Fumonisins / Immunity / Subclinical doses

\section{Introduction}

Mycotoxins are secondary metabolites of fungi that may contaminate animal feeds and human foods. They are frequently detected in grains, but also in fruits, vegetables, nuts and silages. The Food and Agricultural Organization

Correspondence: Dr. Isabelle P. Oswald, INRA-Laboratoire de Pharmacologie-Toxicologie, 180 chemin de Tournefeuille BP 93173, 31027 Toulouse Cedex 3, France

E-mail: isabelle.oswald@toulouse.inra.fr

Fax: $+33-5-61-28-53-10$
Received: August 25, 2010

Revised: November 6, 2010

Accepted: November 25, 2010 estimated that as much as $25 \%$ of the world's agricultural commodities are contaminated with mycotoxins and the economic losses due to mycotoxin contamination are estimated in billions of dollars annually worldwide [1]. Clinical signs caused by mycotoxins range from mortality to slow growth and reduced reproductive efficiency. Consumption

Abbreviations: APC, antigen-presenting cells; BALT, bronchioleassociated lymphoid tissue; DON, deoxynivalenol; FB, fumonisins; HE, hematoxylin-eosin; MAPK, mitogen-activated

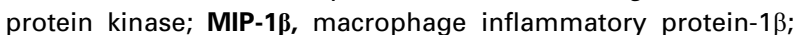
OVA, ovalbumin 
of mycotoxins may also result in impaired immunity and decreased resistance to infectious diseases [2].

Worldwide surveys on the occurrence and contamination levels of mycotoxins in raw materials indicate that toxins produced by Fusarium mold species are of concern [3-5]. Among the fusariotoxins, deoxynivalenol (DON) and fumonisins (FB) are frequently detected with concentrations up to $927 \mathrm{mg} \mathrm{DON} / \mathrm{kg}$ and $300 \mathrm{mg} \mathrm{FB} / \mathrm{kg}$ [4]. Among cereal samples collected from European countries, 54\% were cocontaminated with DON and FB [6]. Similarly, in France, 65\% of the maize kernels harvested during 2004-2006 were cocontaminated with DON and FB (Arvalis-Institut du végétal, unpublished data). These two mycotoxins are of major concern not only in terms of their ubiquitous distribution but also because of their effects on human and animal health.

At high concentrations, FB cause equine leukoencephalomalacia and porcine pulmonary edema, and it is nephroand hepatotoxic and carcinogenic in rats and mice. FB1 has been classified as a potential human carcinogen (class 2B) by the International Agency for Research on Cancer. In humans, consumption of FB-contaminated food has been linked with human esophageal cancer and neural tube defects [7]. Disruption of sphingolipid biosynthesis appears to be one mechanism involved in FB toxicity, with inhibition of ceramide synthase [7] leading to accumulation of sphingoid bases (sphinganine and sphingosine). The effects of ingestioning low doses of FB are less documented but revealed pathological alterations of the lungs and an increase in intestinal colonization by opportunistic pathogenic bacteria in piglets [8-10].

Acute exposure to high doses of DON induces diarrhea, vomiting, leukocytosis and gastrointestinal hemorrhage. Anorexia, growth retardation and immunotoxicity occur in rodents and pigs following chronic DON ingestion [11]. At the cellular level, DON interferes with the active site of peptidyl transferase on ribosomes, and inhibits protein synthesis [11]. Further, binding of DON to the ribosome in eukaryotic cells triggers a "ribotoxic stress response", which involves phosphorylation of the mitogen-activated protein kinases (MAPKs) [12]. MAPK activation modulates the expression of genes associated with the immune response, chemotaxis, inflammation and apoptosis. The cellular and molecular mechanisms of the immunomodulating action of DON have been described in numerous studies using mice and murine cell lines [13]. Depending on the dose and frequency of exposure, DON can be either immunosuppressive or immunostimulatory $[11,14]$. Prolonged ingestion of DON produces elevation of immunoglobulin A in plasma [13-15] while increasing the susceptibility to infectious diseases [11].

The toxicity of combinations of mycotoxins cannot always be predicted based upon their individual toxicities [1]. Interactions between concomitantly occurring mycotoxins can be antagonistic, additive or synergistic. The data on combined toxic effects of mycotoxins are limited and, therefore, the actual combined health risk from exposure to mycotoxins is unknown. Assessment of the interaction of Fusarium myco- toxins has been investigated in vitro on immune cells and intestinal epithelial cells [16, 17]. In vivo experiments have also been done on mice, pigs and poultry using high doses of toxins in which the authors mainly looked for differences in animal performance. Among them, few studies were concerned with the interaction between DON and FB $[18,19]$.

The purpose of this study was to compare the effects of low doses of DON and FB in pigs when fed individually and in combination with particular emphasis on their effects on the immune response. The experimental design was a factorial assay including control feed and feed contaminated with 3 and $6 \mathrm{mg} / \mathrm{kg}$ DON and FB individually and in combination, respectively. These contamination levels correspond to levels that frequently occur naturally in cereals [1]. Results have been reported in terms of both general toxicological parameters including weight gain, hematology, plasma biochemistry and organ histology as well as specific parameters describing immune system responses (total and specific antibody, lymphocyte proliferation, cytokine expression).

\section{Materials and methods}

\subsection{Animals}

All animal experimentation procedures were carried out in accordance with the European Guidelines for the Care and Use of Animals for Research Purposes (Directive 86/609/ EEC). Twenty-four 4-wk-old weaned castrated male pigs (Pietrain/Duroc/Large-white) were obtained locally. Male pigs were used in this protocol as it was previously demonstrated that a greater effect of DON and FB occurs in male pigs compared to female pigs [20]. Animals were acclimatized for $1 \mathrm{wk}$ in the animal facility of the INRA Laboratory of Pharmacology and Toxicology (Toulouse, France), prior to being used in experimental protocols. Six pigs were allocated to each treatment on the basis of body weight. During the 35-day experimental period each treatment group was given free access to water and the assigned diet. The pigs were observed daily and weighed weekly.

\subsection{Experimental diets}

Diets were manufactured at INRA facilities in Rennes (France), and formulated according to the energy and amino acid requirements for piglets. Feed composition is detailed in Table 1. Four different batches were prepared, one control batch and three batches artificially contaminated with the mycotoxins. Two strains of Fusarium, F. graminearum DSM-4528 and F. verticillioides M-3125 were used to produce DON and FB, respectively. These strains were grown separately on rice. FB were produced as previously described [21]. DON was extracted with ethyl acetate, and the extract dried on silica gel 60 (Merck, Darmstadt, Germany). The homogenized extracts contained 24 and 
Table 1. Composition of the experimental diet

\begin{tabular}{lr}
\hline Ingredient (\%) & \\
\hline Wheat & 47.50 \\
Soybean meal & 24.30 \\
Barley & 22.90 \\
Calcium phosphate & 1.12 \\
Calcium carbonate & 1.00 \\
Vitamin and mineral premix ${ }^{a)}$ & 0.50 \\
Vegetable oil & 1.40 \\
Sodium chloride & 0.40 \\
Phytase & 0.01 \\
Lysine & 0.465 \\
Methionine & 0.165 \\
Threonine & 0.195 \\
Tryptophan & 0.045 \\
Composition & \\
Starch (g) & \\
Crude protein (g) & 15.6 \\
Crude fiber (g) & 476.8 \\
Ca (g) & 218.3 \\
P (g) & 37.5 \\
K (g) & 10.5 \\
Net energy (MJ) & 6.5 \\
\hline
\end{tabular}

a) Vitamin A, $2000000 \mathrm{IU} / \mathrm{kg}$; vitamin D3, $400000 \mathrm{IU} / \mathrm{kg}$; vitamin $\mathrm{E}, 4000 \mathrm{mg} / \mathrm{kg}$; vitamin C, $8000 \mathrm{mg} / \mathrm{kg}$; vitamin B1, $400 \mathrm{mg} / \mathrm{kg}$; vitamin K3, $400 \mathrm{mg} / \mathrm{kg}$; iron, $20000 \mathrm{mg} / \mathrm{kg}$; copper, $4000 \mathrm{mg} /$ $\mathrm{kg}$; zinc, $20000 \mathrm{mg} / \mathrm{kg}$; manganese, $8000 \mathrm{mg} / \mathrm{kg}$.

b) Corresponding to $1000 \mathrm{~g}$ dry matter $/ \mathrm{kg}$.

$21 \mathrm{~g} / \mathrm{kg}$ DON and FB, respectively. The extracts containing the mycotoxins were mixed into the vitamin mineral supplements and then incorporated into the cereal mixture before granulation.

The feed was analysed for mycotoxin content by Quantas Analytik (Tulln, Austria) and by using a multi-mycotoxin method [22]. DON, zearalenone and enniatin were found to be naturally present in the cereals used, resulting in concentrations of 500,50 and $100 \mu \mathrm{g} / \mathrm{kg}$ of feed, respectively. All other mycotoxins, including aflatoxins, T-2 toxin, HT-2 toxin and ochratoxin A were below the limit of detection. The mono-contaminated diets contained $2.8 \mathrm{mg}$ of DON $/ \mathrm{kg}$ of feed and $5.9 \mathrm{mg}$ of FB/ $\mathrm{kg}$ of feed $(4.1 \mathrm{mg}$ FB1 $/ \mathrm{kg}+1.8 \mathrm{mg}$ FB2 $/ \mathrm{kg}$ of feed) while the co-contaminated diet contained $3.1 \mathrm{mg}$ of DON and $6.5 \mathrm{mg}$ of FB/ $\mathrm{kg}$ of feed $(4.5 \mathrm{mg} \mathrm{FB} 1 / \mathrm{kg}$ $+2.0 \mathrm{mg} \mathrm{FB} 2 / \mathrm{kg}$ of feed).

\subsection{Experimental design and sample collection}

On the $4^{\text {th }}$ and $16^{\text {th }}$ day of the experiment, all piglets were immunized by subcutaneous inoculation with 1 and $2 \mathrm{mg}$ of ovalbumin (OVA), respectively (Sigma, St-Quentin Fallavier, France), dissolved in sterile PBS and mixed with incomplete Freund's adjuvant (Sigma). At weekly time intervals, blood samples were aseptically collected from the left jugular vein. Blood was collected in tubes containing sodium heparin or
EDTA (Vacutainer ${ }^{\circledR}$, Becton-Dickinson, USA) for blood culture or blood formula, respectively. Plasma samples were obtained after centrifugation of heparinized blood and stored at $-20^{\circ} \mathrm{C}$ for later analysis. After 35 days of dietary exposure to mycotoxins, immediately after electrical stunning, pigs were killed by exsanguination. Samples of lungs, liver and kidneys were collected from all groups and fixed in 10\% buffered formalin for histopathological analysis. In addition, a portion of the spleen was collected from euthanatized animals, flash-frozen in liquid nitrogen and stored at $-80^{\circ} \mathrm{C}$ until processed for measurements of cytokine mRNA.

\subsection{Hematology and biochemistry}

Hematological analysis was carried out using the impedance coulter LH500 (Beckman Coulter, Villepinte, France). Subpopulations of white blood cells (lymphocytes, monocytes, neutrophils, eosinophils and basophils) were also studied and made manually on 100 leukocytes on May-Grünwald Giemsa stained smears.

Plasma concentrations of total proteins, albumin, urea, creatinin, cholesterol, triglycerides and activity of $\gamma$-glutamyl transferase were determined by a Vitros 250 analyzer (Ortho Clinical Diagnostics, Issy les Moulineaux, France) at the Veterinary School of Toulouse (France).

\subsection{Histology}

The tissue pieces were dehydrated through graded alcohols and embedded in paraffin wax. Sections of $3 \mu \mathrm{m}$ were stained with hematoxylin-eosin (HE) for histopathological evaluation. For each organ, three slides per animal were prepared for analysis, and an area of $2000-2500 \mu \mathrm{m}^{2}$ per slide was observed. As displayed in Table 2, microscopic observations led to the identification of different lesions in the different organs, and allowed for establishing a lesion score per animal. Based on a recent method published [23], we calculated the lesion score by taking into account the degree of severity (severity factor) and the extent of each lesion (according to intensity or observed frequency, scored from 0 to 3). For each lesion, the score of the extent was multiplied by the severity factor. For each tissue, the minimal scores were 0 and the maximal scores were 21, 33 and 15 for liver, lung and kidney, respectively (Table 2).

\subsection{Measurement of hepatocyte proliferation}

The cellular proliferation activity was assessed by counting Ki-67-positive nuclei on formalin-fixed embedded liver sections as already described [24]. Briefly, the sections were incubated with the primary antibody (Zymed (South San Francisco, CA, USA) Ki-67 Clone 7B11 - diluted 1:50) at $4{ }^{\circ} \mathrm{C}$ overnight in a humidity chamber; then the secondary 
antibody (Kit Super Picture ${ }^{\mathrm{TM}}$ Zymed) was applied and followed by the addition of a chromogen (3,3'-diaminobenzidine). Finally, the tissue sections were counterstained with hematoxylin and mounted under coverslips using a permanent mounting medium.

The number of Ki-67-positive nuclei among the total of 100 nuclei was counted on the sections under light microscopy at $40 \times$ magnification. The proliferative index was calculated by Ki-67-positive cells/total cells $\times 100$.

Table 2. Establishment of a lesion score - endpoints used to assess histological lesions ${ }^{\text {a) }}$

\begin{tabular}{|c|c|c|}
\hline Tissue & Type of lesions (severity factor) & Maximal score \\
\hline Liver & $\begin{array}{l}\text { Disorganization of hepatic cords (1) } \\
\text { Hepatic cell vacuolization (1) } \\
\text { Apoptosis (2) } \\
\text { Megalocytosis (2) } \\
\text { Nuclear vacuolation (1) }\end{array}$ & 21 \\
\hline Lung & $\begin{array}{l}\text { Alveolar edema (2) } \\
\text { Interstitial pneumonia (2) } \\
\text { BALT depletion (2) } \\
\text { Hypertrophy muscle cell (2) } \\
\text { Hemorrhage (2) } \\
\text { Vascular congestion (1) }\end{array}$ & 33 \\
\hline Kidney & $\begin{array}{l}\text { Nuclear change (1) } \\
\text { Mitosis (1) } \\
\text { Cytoplasmic vacuolization (1) } \\
\text { Tubular casts (1) } \\
\text { Congestion (1) }\end{array}$ & 15 \\
\hline
\end{tabular}

a) The score for each lesion was obtained by multiplying the severity factor with the extent of the lesion. The organ score was then obtained by the sum of each lesion score. Severity factor (or degree of severity), $1=$ mild lesions, 2 = moderate lesions; the extent of each lesion (intensity or observed frequency) was evaluated and scored as $0=$ no lesion, $1=$ low extent, 2 = intermediate extent, 3 = large extent.

\subsection{Measurement of total and specific immunoglobulin subsets}

The total concentration of the immunoglobulin subsets was measured by ELISA as already described [25]. Briefly, the different isotypes were detected with the appropriate peroxidase anti-pig IgA or IgG (Bethyl, Interchim, Montluç on, France) and were quantified by reference to standard curves constructed with known amounts of pig immunoglobulin classes. Titers of specific antibody anti-OVA were also measured by ELISA [14]. Briefly, the anti-OVA antibodies were detected with peroxidase-labeled anti-pig IgG or IgA (Bethyl). Absorbance was read at $450 \mathrm{~nm}$ using an ELISA plate reader (Spectra thermo, Tecan, NC, USA) and the Biolise 2.0 data management software.

\subsection{Determination of lymphocyte proliferative index}

Lymphocyte proliferation was measured on blood samples collected at different times of the experimental period. The quantification was performed in 96-well plates as already described $[15,26]$. The results were expressed as stimulating index of lymphocyte proliferation calculated as counts per minute in stimulated culture/cpm in control non-stimulated culture.

\subsection{Determination of the expression of mRNA encoding for cytokines by real-time PCR}

Tissue RNA was processed in lysing matrix D tubes (MP Biomedicals, Illkirch, France) containing guanidine-thiocyanate acid phenol (Extract-All ${ }^{\circledR}$, Eurobio, les Ulis, France) for use with the FastPrep-24 (MP Biomedicals). Concentrations, integrity and quality of RNA were determined spectrophotometrically $\left(\mathrm{OD}_{260}\right)$ using Nanodrop ND1000 (Labtech International, Paris,

Table 3. Nucleotide sequences of primers for real-time $\mathrm{PCR}^{\mathrm{a})}$

\begin{tabular}{|c|c|c|c|}
\hline Gene & Primer sequence & Genbank no. & References \\
\hline RPL32 & $\begin{array}{l}\mathrm{F}(300 \mathrm{nM}) \text { TGCTCTCAGACCCCTTGTGAAG } \\
\mathrm{R}(300 \mathrm{nM}) \text { TTTCCGCCAGTTCCGCTTA }\end{array}$ & NM_001001636 & {$[46]$} \\
\hline$\beta 2$-microglobulin & $\begin{array}{l}\mathrm{F}(900 \mathrm{nM}) \text { TTCTACCTTCTGGTCCACACTGA } \\
\mathrm{R}(300 \mathrm{nM}) \text { TCATCCAACCCAGATGCA }\end{array}$ & NM_213978 & {$[27]$} \\
\hline IL-12p40 & $\begin{array}{l}\mathrm{F}(300 \mathrm{nM}) \mathrm{GGTTTCAGACCCGACGAACTCT} \\
\mathrm{R}(900 \mathrm{nM}) \text { CATATGGCCACAATGGGAGATG }\end{array}$ & NM_214013 & {$[27]$} \\
\hline IL-8 & $\begin{array}{l}\mathrm{F}(300 \mathrm{nM}) \mathrm{GCTCTCTGTGAGGCTGCAGTTC} \\
\mathrm{R}(900 \mathrm{nM}) \text { AAGGTGTGGAATGCGTATTTATGC }\end{array}$ & NM_213867 & Present study \\
\hline IL-1 $\beta$ & $\begin{array}{l}\mathrm{F}(300 \mathrm{nM}) \mathrm{GAGCTGAAGGCTCTCCACCTC} \\
\mathrm{R}(300 \mathrm{nM}) \text { ATCGCTGTCATCTCCTTGCAC }\end{array}$ & NM_001005149 & [27] \\
\hline MIP-1 $\beta$ & $\begin{array}{l}\mathrm{F}(300 \mathrm{nM}) \text { AGCGCTCTCAGCACCAATG } \\
\mathrm{R}(300 \mathrm{nM}) \text { AGCTTCCGCACGGTGTATG }\end{array}$ & AJ311717 & Present study \\
\hline IL-6 & $\begin{array}{l}\mathrm{F}(300 \mathrm{nM}) \text { GGCAAAAGGGAAAGAATCCAG } \\
\mathrm{R}(300 \mathrm{nM}) \text { CGTTCTGTGACTGCAGCTTATCC }\end{array}$ & NM_214399 & Present study \\
\hline
\end{tabular}

a) RPL32, ribosomal protein L32. 
France). Besides this inspection, a 200 ng sample of RNA was analyzed by electrophoresis. The reverse transcription and realtime PCR steps were performed as already described [26]. RNA non-reverse transcripted was used as the non-template control for verification of a no genomic DNA amplification signal. Specificity of PCR products was checked out at the end of the reaction by analyzing the curve of dissociation. In addition, the size of amplicons was verified by electrophoresis. The sequences of the primers used are detailed in Table 3. Primers for macrophage inflammatory protein-1 $\beta$ (MIP-1 $\beta$ ), IL-8 and IL-6 detection were designed using Primer Express ${ }^{\mathbb{R}}$ software (Applied Biosystems, Courtaboeuf, France). Primers were purchased from Invitrogen (Cergy Pontoise, France). Amplification efficiency and initial fluorescence were determined by Data Analysis for Real Time-PCR method; then values obtained were normalized by both house-keeping genes, $\beta 2$-microglobulin and ribosomal protein L32, and finally, gene expression was expressed relative to the control group as already described [27].

\subsection{Statistics}

Following the Fisher test on equality of variances, one-way ANOVA was used to analyze the differences between the different groups of animals at each time point. $p$-Values of 0.05 were considered significant.

Table 4. Individual or combined effects of DON and FB on weight gain $^{\text {a) }}$

\begin{tabular}{|c|c|c|c|c|}
\hline \multirow{2}{*}{$\begin{array}{l}\text { Body } \\
\text { weight } \\
\text { gain/day } \\
\text { (kg) }\end{array}$} & \multicolumn{4}{|c|}{ Animal diets } \\
\hline & Control & DON & FB & $\mathrm{DON}+\mathrm{FB}$ \\
\hline $\begin{array}{l}\text { Days } \\
\qquad 1-14\end{array}$ & $0.36 \pm 0.05^{a}$ & $0.35 \pm 0.03^{a}$ & $0.43 \pm 0.05^{\mathrm{a}}$ & $0.32 \pm 0.07^{\mathrm{a}}$ \\
\hline $\begin{array}{l}\text { Days } \\
\qquad 14-35\end{array}$ & $0.76 \pm 0.05^{a}$ & $0.65 \pm 0.03^{a}$ & $0.74 \pm 0.06^{\mathrm{a}}$ & $0.68 \pm 0.03^{a}$ \\
\hline
\end{tabular}

a) Results are expressed as mean \pm SEM for five animals.

\section{Results}

\subsection{Individual or combined effects of DON and FB on weight gain, hematological and biochemical parameters}

During the experiment, piglets were weighed weekly and as reported in Table 4, ingestion of individual or combined DON- and FB-contaminated diets did not significantly impair animal growth.

At the end of the experiment, blood samples were taken from all piglets to investigate the effects of mycotoxins on hematological and biochemical variables (Tables 5 and 6). Piglets fed either FB- or FB+DON-contaminated diets displayed a significant decrease in neutrophil number (Table 5). An increase in creatinin concentration $(p=0.047)$ and a decrease in albumin concentration $(p=0.015)$ was also observed in the animal groups fed with FB- or DONcontaminated diets, respectively. These alterations were not observed in animals fed the diet contaminated with both toxins (Table 6).

\subsection{Individual or combined effects of DON and FB on organ histopathology}

Liver, lungs and kidneys were collected at the end of the trial for histopathological analysis. The lesions observed in these three organs were mild to moderate for animal fed any of the three contaminated diets (DON, FB, DON+FB) (Fig. 1).

The main histological lesions observed in the livers were a disorganization of hepatic cords, cytoplasmatic and nuclear vacuolization of hepatocytes and megalocytosis (Figs. 1A and B). Piglets fed either DON- or FB-contaminated diets displayed significant liver lesions when compared to animals fed the control diet. The lesion score was further increased for animals fed diet contaminated with both toxins. The proliferation of hepatocytes was assessed by counting Ki-67-positive cells in liver sections.

Table 5. Individual or combined effects of DON and FB on hematological parameters ${ }^{\text {a) }}$

\begin{tabular}{|c|c|c|c|c|}
\hline \multirow[t]{2}{*}{ Hematological parameters } & \multicolumn{4}{|c|}{ Animal diets (wk 6) } \\
\hline & Control & DON & FB & $\mathrm{DON} \pm \mathrm{FB}$ \\
\hline White blood cells (thousands/ $\mu \mathrm{L}$ ) & $21.2 \pm 1.9^{a}$ & $19.6 \pm 2.3^{a}$ & $20.3 \pm 2.8^{a}$ & $18.2 \pm 1.6^{a}$ \\
\hline Lymphocytes (thousands/ $\mu \mathrm{L}$ ) & $12.4 \pm 1.9^{a}$ & $11.4 \pm 1.4^{\mathrm{a}}$ & $14.7 \pm 2.1^{a}$ & $12.6 \pm 1.0^{a}$ \\
\hline Neutrophils (thousands/ $\mu \mathrm{L}$ ) & $7.3 \pm 1.1^{\mathrm{a}}$ & $7.0 \pm 1.1^{a, b}$ & $4.5 \pm 0.9^{b}$ & $4.6 \pm 0.6^{b}$ \\
\hline Red blood cells (thousands $/ \mu \mathrm{L}$ ) & $6.2 \pm 0.3^{a}$ & $5.7 \pm 0.2^{\mathrm{a}}$ & $6.1 \pm 0.4^{a}$ & $5.9 \pm 0.4^{a}$ \\
\hline Mean corpuscular volume (fL) & $47.6 \pm 0.8^{a}$ & $47.1 \pm 0.7^{\mathrm{a}}$ & $46.2 \pm 0.5^{\mathrm{a}}$ & $50.4 \pm 1.9^{a}$ \\
\hline Hematocrit $(\%)$ & $29.8 \pm 1.6^{a}$ & $27.0 \pm 0.5^{\mathrm{a}}$ & $28.0 \pm 1.9^{a}$ & $29.5 \pm 1.6^{a}$ \\
\hline Hemoglobin $(\mathrm{g} / \mathrm{dL})$ & $9.6 \pm 0.5^{\mathrm{a}}$ & $9.0 \pm 0.2^{a}$ & $9.4 \pm 0.5^{\mathrm{a}}$ & $9.7 \pm 0.5^{\mathrm{a}}$ \\
\hline Mean corpuscular hemoglobin (pg) & $15.4 \pm 0.2^{\mathrm{a}}$ & $15.6 \pm 0.2^{\mathrm{a}}$ & $15.6 \pm 0.2^{\mathrm{a}}$ & $16.5 \pm 0.8^{a}$ \\
\hline Mean corpuscular hemoglobin concentration (\%) & $32.4 \pm 0.4^{\mathrm{a}}$ & $33.2 \pm 0.3^{\mathrm{a}}$ & $33.8 \pm 0.6^{\mathrm{a}}$ & $32.8 \pm 0.4^{\mathrm{a}}$ \\
\hline
\end{tabular}

a) Results are expressed as mean \pm SEM for six animals. Values in rows with different letters are significantly different. 
Table 6. Individual or combined effects of DON and FB on biochemical parameters ${ }^{\text {a) }}$

\begin{tabular}{|c|c|c|c|c|}
\hline \multirow[t]{2}{*}{ Biochemical parameters } & \multicolumn{4}{|c|}{ Animal diets (wk 6) } \\
\hline & Control & DON & FB & $\mathrm{DON}+\mathrm{FB}$ \\
\hline Urea (mmol/L) & $3.8 \pm 0.4^{a}$ & $3.3 \pm 0.4^{\mathrm{a}}$ & $4.2 \pm 0.3^{\mathrm{a}}$ & $4.0 \pm 0.4^{\mathrm{a}}$ \\
\hline Creatinin $(\mu \mathrm{mol} / \mathrm{L})$ & $102.5 \pm 5.3^{a}$ & $98.0 \pm 4.1^{\mathrm{a}}$ & $120.5 \pm 5.6^{b}$ & $101.6 \pm 5.5^{\mathrm{a}}$ \\
\hline Cholesterol (mmol/L) & $2.6 \pm 0.2^{\mathrm{a}}$ & $2.4 \pm 0.2^{\mathrm{a}}$ & $2.3 \pm 0.1^{\mathrm{a}}$ & $2.3 \pm 0.1^{\mathrm{a}}$ \\
\hline Triglycerides (mmol/L) & $0.51 \pm 0.07^{\mathrm{a}}$ & $0.34 \pm 0.04^{a}$ & $0.39 \pm 0.06^{\mathrm{a}}$ & $0.41 \pm 0.06^{\mathrm{a}}$ \\
\hline Total proteins $(\mathrm{g} / \mathrm{L})$ & $59.8 \pm 1.0^{\mathrm{a}}$ & $57.1 \pm 2.1^{a}$ & $59.9 \pm 2.5^{\mathrm{a}}$ & $57.6 \pm 2.5^{\mathrm{a}}$ \\
\hline Albumin $(\mathrm{g} / \mathrm{L})$ & $34.3 \pm 0.7^{\mathrm{a}}$ & $29.2 \pm 1.5^{\mathrm{b}}$ & $35.1 \pm 2.1^{\mathrm{a}}$ & $32.8 \pm 2.1^{\mathrm{a}, \mathrm{b}}$ \\
\hline GGT (IU/L) & $65.4 \pm 8.6^{\mathrm{a}}$ & $88.6 \pm 14.4^{\mathrm{a}}$ & $79.4 \pm 15.0^{a}$ & $77.0 \pm 11.5^{\mathrm{a}}$ \\
\hline
\end{tabular}

a) GGT, $\gamma$-glutamyl transferase. Results are expressed as mean \pm SEM for five animals. Values in rows with different letters are significantly different.

The mean proliferation indexes were $16.4 \pm 1.5$ in the control group, $18.8 \pm 3.3$ in the DON-treated group, $22.8 \pm 1.7$ in the FB-treated group and $39.4 \pm 12.8$ in the DON +FB-treated group $(p<0.001, p<0.01$ and $p<0.05$, for comparison between $\mathrm{DON}+\mathrm{FB}$ and control, DON or FB groups, respectively).

In the lungs, depletion of bronchiole-associated lymphoid tissue (BALT) and vascular disorders (peribronchiolar, alveolar hemorrhage and congestion) were the most frequent observed lesions (Fig. 1C). Of note, BALT structures were checked and were present in all individual pigs, evaluated in a comparable size and area between experimental groups. Alveolar edema showed a focal presentation (Fig. 1D). As demonstrated by the lesion scores, lung lesions were only observed in animals receiving FB- or FB+DON-contaminated diets. In this latter group, a medial hypertrophy of pulmonary arterioles was observed in half of the animals.

Lesions in the kidneys were mild as indicated by low lesion scores. The main observed lesions were degenerative changes in tubular epithelial cells (vacuolization of the cytoplasm and nucleus, Figs. $1 \mathrm{E}$ and F) and interstitial infiltration of lymphocytes with a focal or multifocal pattern. These lesions were observed in animals receiving diets contaminated with DON, FB and both toxins.

\subsection{Individual or combined effects of DON and FB on the immune response}

The main objective of this study was to assess the individual and combined effects of DON and FB on the immune response in piglets. Ingestion of diets contaminated with individual or combined mycotoxins neither altered the total plasmatic concentration of IgG and IgA nor modulated the lymphocyte proliferation upon concanavalin A stimulation (data not shown).

The immunization protocol with OVA allowed us to investigate the effects of mycotoxins on antigen-specific immunity $[14,26]$. The ingestion of diets contaminated with DON or FB individually or in combination significantly altered the production of immunoglobulins after OVA vaccination (Fig. 2). Animals fed mycotoxin-contaminated diets displayed a reduced anti-OVA IgG concentration in their plasma. However, because of high individual variability, the decrease was only significant for animals receiving FB-contaminated feed. This decrease was further pronounced for animals fed the diet containing both toxins. Concerning the effect of mycotoxins on the specific IgA concentration, as expected, we observed a significant increase of this immunoglobulin isotype in piglets fed the DON-contaminated diet. However, when DON was fed in combination with FB, the increase of plasmatic-specific IgA concentration was not observed (Fig. 2).

As already observed $[14,26]$, piglets receiving the control diet displayed a significant increase in the lymphocyte proliferation upon OVA stimulation after the second immunization (1.4-fold increase, $p=0.191$; 3.3 -fold increase, $p=0.012$ and 2.8-fold increase, $p=0.020$ at days 21, 28 and 35 of the experiment, respectively). By contrast, the lymphocyte proliferation upon OVA stimulation in the animals receiving any of the three contaminated diets (DON, FB and $\mathrm{DON}+\mathrm{FB}$ ) remained as low as in control unstimulated lymphocytes (Fig. 3).

\subsection{Individual or combined effects of DON and FB on the expression of cytokines}

Cytokines play a key role in regulating both humoral and cell-mediated immunity. The mRNA expression of five cytokines (IL-12p40, IL-8, IL-1 $\beta$, IL-6 and MIP-1 $\beta$ ) was measured by real-time RT-PCR in spleen samples collected at the end of the experiment (Fig. 4). Animals fed the diet containing both DON and FB demonstrated a significant decrease in mRNA for all tested cytokines when compared to the control pigs $(p=0.009$ for IL-8; $p=0.035$ for IL-1 $\beta ; p=0.004$ for IL-6; $p=0.031$ for IL-12p40; $p=0.006$ for MIP-1 $\beta$ ). Animals fed the diet contaminated with DON demonstrated a significant decrease in mRNA encoding for IL-8, whereas animals fed the diet contaminated with FB demonstrated a significant decrease in mRNA encoding for IL-1 $\beta$ and IL-6. 

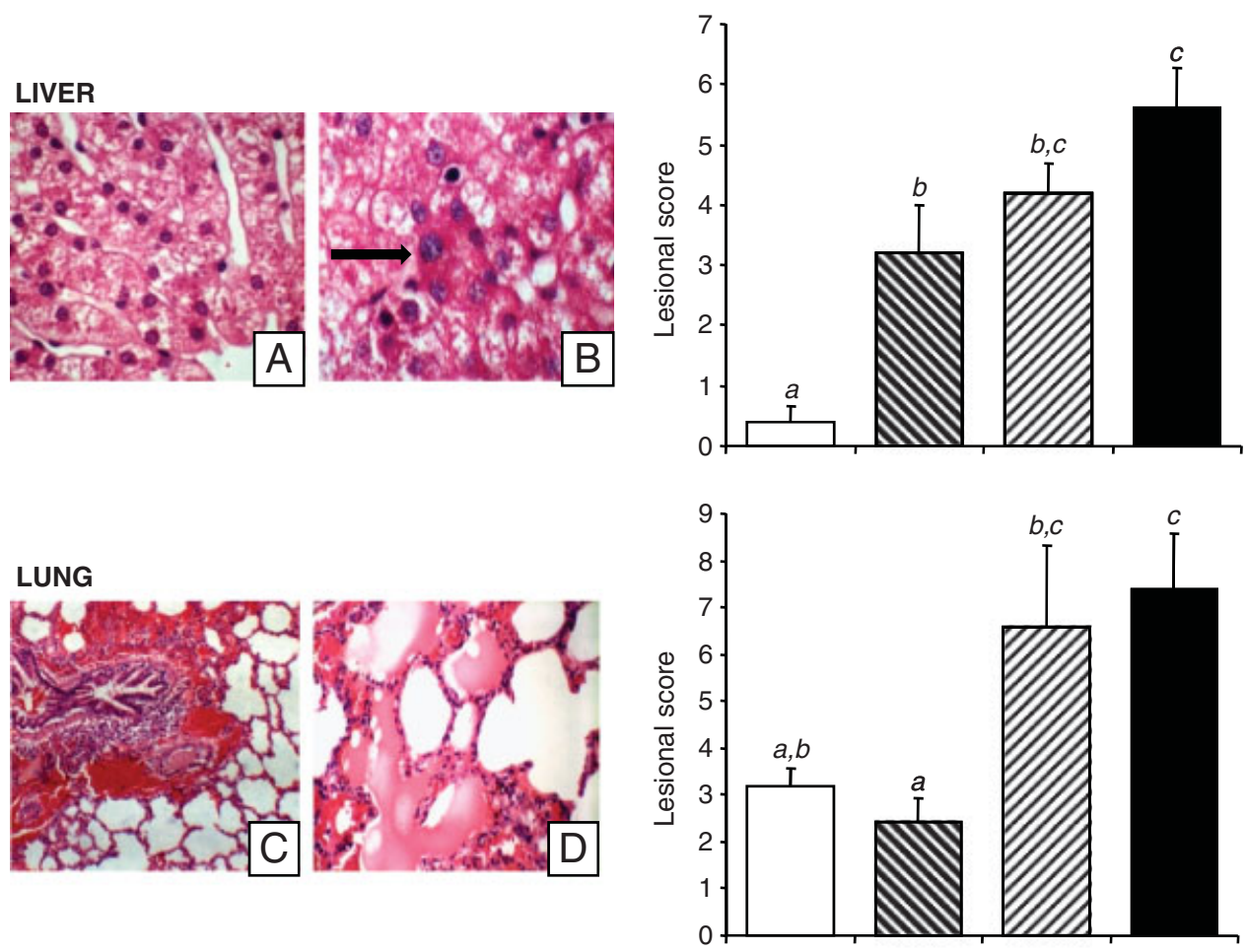

Figure 1. Individual and combined effects of DON and FB on liver, lungs and kidneys. Pigs received a control diet ( $\square$ ), or a DON-contaminated diet ( $\mathbf{N})$, or an FB-contaminated diet ( $/ / 1)$ or a diet contaminated with both toxins ( $)$. (A) Hepatocyte cytoplasmatic vacuolization and (B) hepatocyte

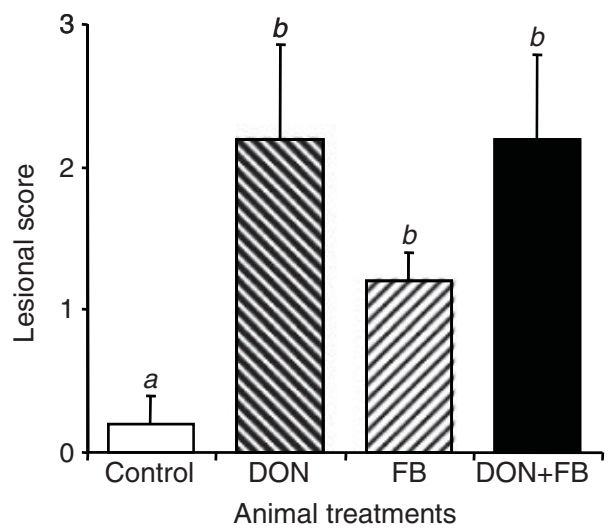
megalocytosis (arrow). HE $40 \times$. (C) BALT depletion and peribronchiolar hemorrhage. HE $10 \times$ and (D) Alveolar edema. HE $40 \times$. (E) Cytoplasmatic vacuolization of tubular cells and mitosis (arrow) and (F) nuclear change (arrow) in tubular cells. HE $40 \times$. Lesion scores were established after histological examination according to the severity and the extent of the lesions. Values are mean \pm SEM for five animals.

\section{Discussion}

In the present 5-wk study, piglets were exposed to low doses of two major Fusarium mycotoxins, DON and FB, at levels commonly found in crops. Most of the current data concerning the effects of DON or FB on animals, including rodents, have been obtained using highly mono-contaminated feeds $[9,12,13,28]$. It was thus of interest to determine the effect of ingestion of feeds contaminated with low level of these toxins, present alone or in combination, on zootechnical, hematological, biochemical, histopathological and immune parameters of piglets.

We did not observe any effect of mycotoxin-contaminated diets (DON, FB, DON $+F B$ ) on the body weight gain of the animals. Considering the low contamination levels we used, these results are not surprising. Indeed, no effect on body weight gain has been reported in pigs and in poultry fed with up to $70 \mathrm{mg} \mathrm{FB} / \mathrm{kg}$ feed $[18,29]$. The effects of DON on body weight gain are more controversial, especially in pigs. Some studies indicate that dietary concentrations of DON above $1-2 \mathrm{mg} / \mathrm{kg}$ have an effect on weight gain, whereas in other studies no effect is observed for up to $4.5 \mathrm{mg} \mathrm{DON} / \mathrm{kg}$ feed [30]. A weight gain reduction has also been described when DON and FB were given together to growing barrows [18]. However, in this study, the dose of FB was ten-fold higher than the one used in the present experiment.

Exposure of piglets to low doses of either DON or FB did not have a major impact on the hematological and biochemical parameters investigated. For blood hematology, only a reduction in neutrophil numbers was noticed in FBexposed piglets. This observation is in relation with the 

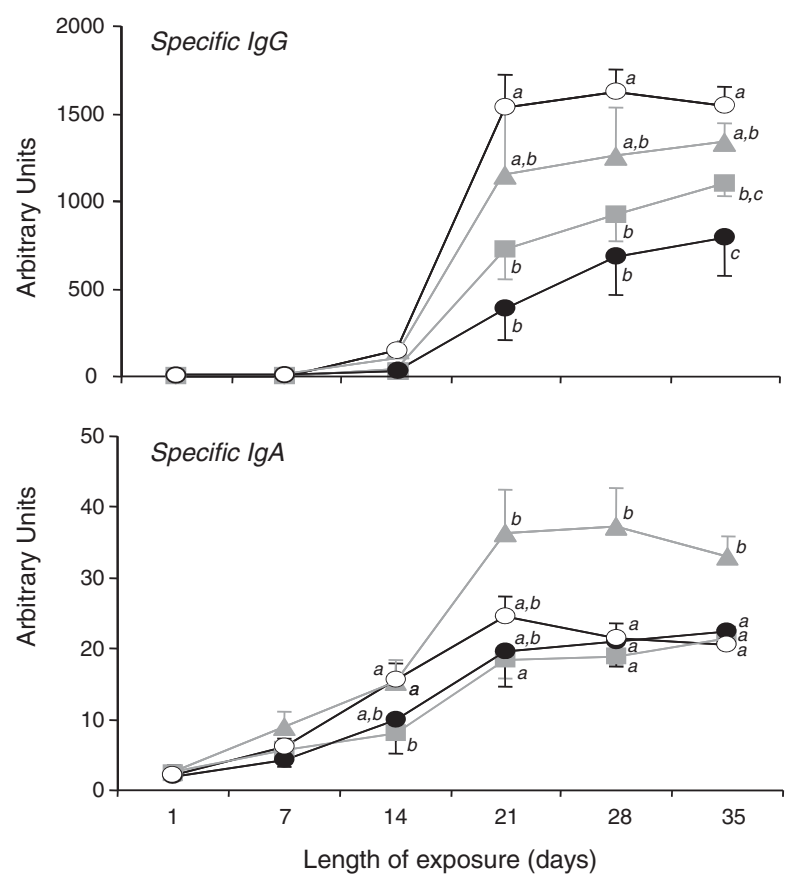

Figure 2. Individual and combined effects of DON and FB on plasma concentrations of specific immunoglobulin ( $\lg A$ and $\lg G$ ) anti-OVA. Pigs received a control $\operatorname{diet}(O)$, or a DON-contaminated diet ( $\mathbf{A})$, or an FB-contaminated diet $(\square)$ or a contaminated diet with both toxins (๑). At days 4 and 16 of the trial, animals receiving either control or contaminated feeds were subcutaneously immunized with OVA. Plasma samples were collected weekly and the levels of IgA and IgG specific for OVA were determined by ELISA and normalized against a standardized reference plasma. Values are mean \pm SEM for five animals. Statistics are mentioned when significant changes were observed.

reduced viability measured in human neutrophils exposed in vitro to this toxin [31]. For blood biochemistry, there was a decrease in albumin concentration in DON-exposed animals and an increase in creatinin concentration in FB-exposed piglets in accordance with previously published studies $[18,20,32,33]$. Ingestion of diets co-contaminated with DON and FB had less effect on hematology and biochemistry parameters than did mono-contaminated diets. Some studies have already reported a weaker effect on plasma biochemical parameters for piglets fed multi-contaminated diets than for piglets receiving mono-contaminated feeds $[18,19]$, which suggests an opposite effect of the two mycotoxins.

Despite the absence of effects on zootechnical, hematological and biochemical parameters, ingestion of feeds contaminated with low concentrations of either DON or FB induced histopathological lesions in liver, lungs and kidneys. Toxic effects of FB on liver have been reported in several papers using highly contaminated materials $[9,28]$. The effects included a disorganization of hepatic cords, hepatocellular vacuolation, megalocytosis, apoptosis,

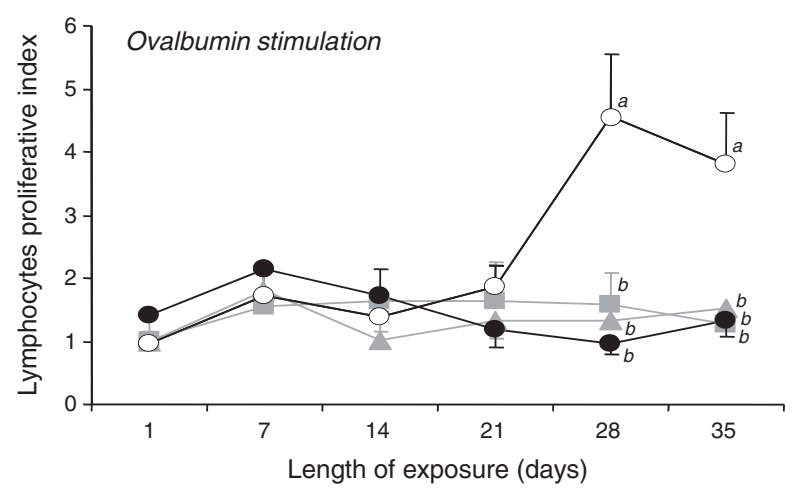

Figure 3. Individual and combined effects of DON and FB on lymphocyte-specific (OVA) proliferation. Pigs received a control $\operatorname{diet}(O)$, or a DON-contaminated $\operatorname{diet}(\mathbf{\Delta})$, or an FB-contaminated diet $(\square)$ or a contaminated diet with both toxins (O). At days 4 and 16 of the trial, animals were subcutaneously immunized with OVA. Blood samples were taken weekly to measure the lymphocyte proliferation. Results are expressed as stimulating index of lymphocyte proliferation calculated as counts per minute in stimulated culture/cpm in control non-stimulated culture. Values are mean \pm SEM for five animals. Statistics are mentioned when significant changes were observed.

necrosis and cell proliferation. In the present study, it was observed that even when present at a lower dose, FB induced similar liver histopathological lesions. Liver lesions, such as hepatic cell vacuolation, were also observed in piglets fed the DON-contaminated diet [34]. These lesions were not associated with major biochemical alterations. The biological meaning of the hepatic lesions remains to be determined. Histopathological analysis of lung confirmed that this is a target organ for FB. At high doses $(\geq 92 \mathrm{mg} / \mathrm{kg}$ of feed for 4-7 days), FB induce lethal pulmonary edema in swine [9]. In the present study, the low dose of FB also induced pulmonary damages, mainly BALT depletion and vascular disorders. By contrast, when present at a low dose in the diet, DON did not induce any lesion in the lung.

For the three organs investigated, the damages elicited from the ingestion of the diet co-contaminated with DON and FB were equal to or higher than the ones elicited by the ingestion of a single mycotoxin. Very few publications analyzed the effects of mixed mycotoxins on histopathological parameters, especially at low doses [35, 36]. The histopathological lesions observed in the lungs of co-exposed piglets were slightly more pronounced than the ones observed in the lungs of FB-exposed animals. In the liver, ingestion of the co-contaminated diet induced significantly higher lesions than ingestion of either of the monocontaminated feeds as demonstrated by the lesion score and the hepatocyte proliferation. One explanation for the high liver toxicity of DON and FB when present simultaneously could be the higher absorption of FB in the presence of DON. Indeed, DON has recently been shown to decrease the barrier function of the intestine [37]. Thus, ingestion of 

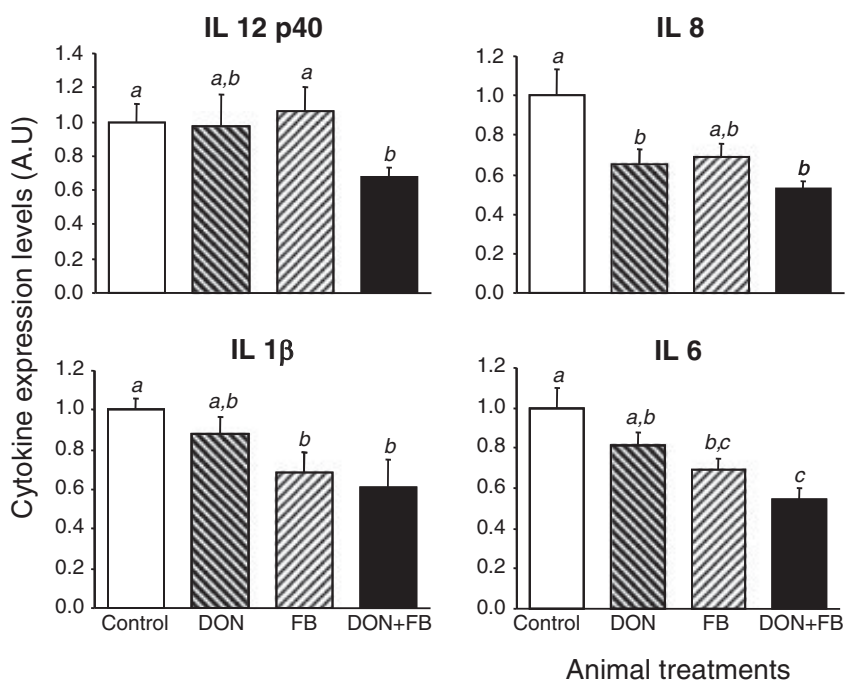

DON may increase the absorption of FB, mycotoxins already known to be poorly absorbed [7, 9].

The main objective of this study was to investigate the effect of low doses of DON or FB ingested separately or in combination on the immune response of piglets. As in previous experiments, it was observed that at low doses, mycotoxins have little or no effect on the total non-specific immune responses as measured by lymphocyte proliferation upon mitogenic stimulation and the plasmatic concentration of immunoglobulin classes. Immunization protocols, as already described, were needed to observe an effect of low doses of mycotoxins, fed either alone or in combination on the immune responses [14, 26, 38].

A very low proliferative index, close to the one observed in unstimulated cells, was obtained in cells isolated from animals fed either DON-, FB- or DON+FB-contaminated diets. This alteration of lymphocyte proliferation might be due to an effect of these toxins on antigen-presenting cells (APC) as suggested by recent in vitro studies on monocytederived APC treated with DON [39, 40] or in vivo studies with piglets acutely exposed to FB [27].

Interestingly, the diet co-contaminated with DON and FB appeared to be able to counteract the increased level of specific IgA observed in the animal receiving only the DONcontaminated diet. Indeed, consumption of the DON-contaminated diet increased the level of specific IgA in the plasma $[11,14]$ whereas ingestion of diet contaminated with both DON and FB did not alter the plasma level of this immunoglobulin isotype. We can hypothesize that FB interfere with the DON-induced IgA elevation at the intestinal level through its action on sphingolipids. Indeed, FB are known to disrupt the sphingolipid metabolism leading to depletion of ceramide and all ceramide-derived complex sphingolipids, such as sphingomyelin [41, 42]. This latter compound has been recently reported to control the amount of IgA in the large intestine [43].

Depending on the mycotoxin, DON or FB significantly impaired the specific IgG concentration and the level of

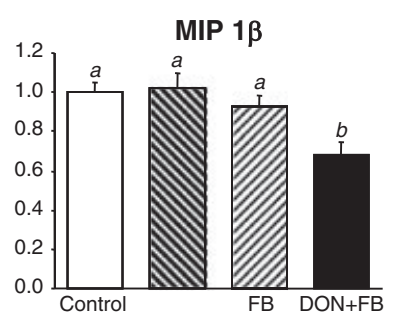

Figure 4. Individual and combined effects of DON and FB on splenic mRNA expression of cytokines. Pigs received a control diet $(\square)$, or a DONcontaminated diet ( $\mathbf{N})$, or an FB-contaminated diet ( $/(1)$ or a diet contaminated with both toxins ( $)$. Quantification of the relative cytokine mRNA level for each sample is expressed in arbitrary units (A.U). Values are mean \pm SEM for five animals.

cytokine expression. Nonetheless, the diet co-contaminated with DON and FB led to a strong decrease of specific IgG concentration, greater than the one observed in animals receiving only one toxin. Similar effects were observed for the five cytokines investigated, where the impact of the cocontaminated diet was higher than either of the monocontaminated diets. Several studies investigated cytokine expression during chronic exposure to mycotoxins $[14,15$, $25,27]$, but none of them concern the co-contamination. Cytokines are important mediators in the immune response. Expressions of IL- 8 and MIP-1 $\beta$, which are involved in cell chemotaxis, were significantly inhibited in animals fed the co-contaminated diet, and it can be anticipated that in these animals, recruitment and migration of APC to peripheral lymphoid tissue were reduced. Similarly, the decreased mRNA levels of IL-1 $\beta$ and IL- 6 mRNA in piglets receiving the co-contaminated diet may lead to a defective antigen presentation and an impaired activation of lymphocytes and may explain the decreased IgG response observed in this study.

Find a mechanism that explains the observed effects after the combination of both toxins is not easy, but at the cellular level, it might be hypothesized that MAPK activation could be involved. Indeed, both DON and FB have been shown to activate MAPKs [12, 44], and these kinases are well known to modulate numerous physiological processes, such as cell growth, apoptosis or immune response [45].

In conclusion, chronic exposure to low doses of DON or $\mathrm{FB}$, either alone or in combination did not elicit important clinical signs (body weight gain, hematology, biochemistry), but induced microscopic lesions and altered the immune response, especially when the mycotoxins were fed in combination. The modulation of the immune response was only observed when the immune system was activated. Considering (i) that vaccination or infection by pathogens is a common situation encountered in animal husbandry and (ii) the natural occurrence of these mycotoxins in feedstuffs, the present experiment suggests a significant disruption in 
the establishment of an appropriate specific response in animals receiving mycotoxin-contaminated diets. This study also highlights the complexity of mycotoxin interactions; some effects are not enhanced by the combination of toxins (biochemistry, lung and kidney lesions, specific IgA content), while others are (specific IgG content, cytokines expression, liver lesions). These results may have some impact on the current regulation/recommendation that only takes into account individual mycotoxins and not multimycotoxin contamination.

B.G. was supported by a doctoral fellowship (CIFRE 065/ 2007), jointly financed by the Biomin company, ANRT (Association Nationale de la Recherche Technique) and INRA (Institut National de la Recherche Agronomique). This study was supported in part by a CAPES/COFECUB Grant (No. 593/08) and a CNDT Grant (No. 472048/2008-2). The authors thank M. Kainz and E. Pichler from Quantas Analytik $\mathrm{GmbH}$ and M. Sulyok from IFA-Tulln for mycotoxin analysis, G. Häubl and G. Jaunecker from Biopure (Romer Labs) for mycotoxin production, G. Guillemois from INRA Rennes for his assistance with feed manufacture, P. Pinton, J. Laffitte, R. Solinhac and M. Gallois for technical assistance during the animal experiments and Dr. Mike Watkins for his help with the English text.

The authors have declared no conflict of interest.

\section{References}

[1] CAST, Council for Agricultural Science and Technology, Mycotoxins, Risks in Plant, Animal, and Human System, Task Force Report 139, Ames lowa 2003.

[2] Oswald, I. P., Comera, C., Immunotoxicity of mycotoxins. Rev. Med. Vet. 1998, 149, 585-590.

[3] Binder, E. M., Tan, L. M., Chin, L. J., Handl, J., Richard, J., Worldwide occurrence of mycotoxins in commodities, feeds and feed ingredients. Anim. Feed Sci. Technol. 2007, 137, 265-282.

[4] Placinta, C. M., D'Mello, J. P. F., Macdonald, A. M. C., A review of worldwide contamination of cereal grains and animal feed with Fusarium mycotoxins. Anim. Feed Sci. Technol. 1999, 78, 21-37.

[5] Schothorst, R. C., van Egmond, H. P., Report from SCOOP task 3.2.10 "collection of occurrence data of Fusarium toxins in food and assessment of dietary intake by the population of EU member states" - Subtask: trichothecenes. Toxicol. Lett. 2004, 153, 133-143.

[6] Monbaliu, S., Van Poucke, C., Detavernier, C., Dumoulin, F. et al., Occurrence of mycotoxins in feed as analyzed by a multi-mycotoxin LC-MS/MS method. J. Agric. Food Chem. 2010, 58, 66-71.

[7] Voss, K. A., Smith, G. W., Haschek, W. M., Fumonisins: toxicokinetics, mechanism of action and toxicity. Anim. Feed Sci. Technol. 2007, 137, 299-325.
[8] Halloy, D. J., Gustin, P. G., Bouhet, S., Oswald, I. P., Oral exposure to culture material extract containing fumonisins predisposes swine to the development of pneumonitis caused by Pasteurella multocida. Toxicology 2005, 213, 34-44.

[9] Haschek, W. M., Gumprecht, L. A., Smith, G., Tumbleson, M. E., Constable, P. D., Fumonisin toxicosis in swine: an overview of porcine pulmonary edema and current perspectives. Environ. Health Perspect. 2001, 109, 251-257.

[10] Oswald, I. P., Desautels, C., Laffitte, J., Fournout, S. et al., Mycotoxin fumonisin B-1 increases intestinal colonization by pathogenic Escherichia coli in pigs. Appl. Environ. Microbiol. 2003, 69, 5870-5874.

[11] Pestka, J. J., Smolinski, A. T., Deoxynivalenol: toxicology and potential effects on humans. J. Toxicol. Env. Health Crit. Rev. 2005, 8, 39-69.

[12] Zhou, H. R., Islam, Z., Pestka, J. J., Rapid, sequential activation of mitogen-activated protein kinases and transcription factors precedes proinflammatory cytokine mRNA expression in spleens of mice exposed to the trichothecene vomitoxin. Toxicol. Sci. 2003, 72, 130-142.

[13] Pestka, J. J., Zhou, H. R., Moon, Y., Chung, Y. J., Cellular and molecular mechanisms for immune modulation by deoxynivalenol and other trichothecenes: unraveling a paradox. Toxicol. Lett. 2004, 153, 61-73.

[14] Pinton, P., Accensi, F., Beauchamp, E., Cossalter, A. M. et al., Ingestion of deoxynivalenol (DON) contaminated feed alters the pig vaccinal immune responses. Toxicol. Lett. 2008, 177, 215-222.

[15] Accensi, F., Pinton, P., Callu, P., Abella-Bourges, N. et al., Ingestion of low doses of deoxynivalenol does not affect hematological, biochemical, or immune responses of piglets. J. Anim. Sci. 2006, 84, 1935-1942.

[16] Kouadio, J. H., Dano, S. D., Moukha, S., Mobio, T. A., Creppy, E. E., Effects of combinations of Fusarium mycotoxins on the inhibition of macromolecular synthesis, malondialdehyde levels, DNA methylation and fragmentation, and viability in Caco-2 cells. Toxicon 2007, 49, 306-317.

[17] Marzocco, S., Russo, R., Bianco, G., Autore, G., Severino, L., Pro-apoptotic effects of nivalenol and deoxynivalenol trichothecenes in J774A.1 murine macrophages. Toxicol. Lett. 2009, 189, 21-26.

[18] Harvey, R. B., Edrington, T. S., Kubena, L. F., Elissalde, M. H. et al., Effects of dietary fumonisin B-1-containing culture material, deoxynivalenol-contaminated wheat, or their combination on growing barrows. Am. J. Vet. Res. 1996, 57, 1790-1794.

[19] Kubena, L. F., Edrington, T. S., Harvey, R. B., Buckley, S. A. et al., Individual and combined effects of fumonisin B1 present in Fusarium moniliforme culture material and T-2 toxin or deoxynivalenol in broiler chicks. Poult. Sci. 1997, 76, 1239-1247.

[20] Marin, D. E., Taranu, I., Pascale, F., Lionide, A. et al., Sexrelated differences in the immune response of weanling piglets exposed to low doses of fumonisin extract. $B r$. J. Nutr. 2006, 95, 1185-1192. 
[21] Leslie, J. F., Plattner, R. D., Desjardins, A. E., Klittich, C. J. R., Fumonisin B1 production by strains from different mating populations of Gibberella-Fujikuroi (Fusarium Section Liseola). Phytopathology 1992, 82, 341-345.

[22] Sulyok, M., Krska, R., Schuhmacher, R., A liquid chromatography/tandem mass spectrometric multi-mycotoxin method for the quantification of 87 analytes and its application to semi-quantitative screening of moldy food samples. Anal. Bioanal. Chem. 2007, 389, 1505-1523.

[23] Kolf-Clauw, M., Castellote, J., Joly, B., Bourges-Abella, N. et al., Development of a pig jejunal explant culture for studying the gastrointestinal toxicity of the mycotoxin deoxynivalenol: histopathological analysis. Toxicol. Vitro 2009, 23, 1580-1584.

[24] Makino, H., Togo, S., Kubota, T., Morioka, D. et al., A good model of hepatic failure after excessive hepatectomy in mice. J. Surg. Res. 2005, 127, 171-176.

[25] Taranu, I., Marin, D. E., Bouhet, S., Pascale, F. et al., Mycotoxin fumonisin B-1 alters the cytokine profile and decreases the vaccinal antibody titer in pigs. Toxicol. Sci. 2005, 84, 301-307.

[26] Meissonnier, G. M., Pinton, P., Laffitte, J., Cossalter, A. M. et al., Immunotoxicity of aflatoxin B1: Impairment of the cellmediated response to vaccine antigen and modulation of cytokine expression. Toxicol. Appl. Pharmacol. 2008, 231, 142-149.

[27] Devriendt, B., Gallois, M., Verdonck, F., Wache, Y. et al., The food contaminant fumonisin B-1 reduces the maturation of porcine $\operatorname{CD} 11 \mathrm{R} 1(+)$ intestinal antigen presenting cells and antigen-specific immune responses, leading to a prolonged intestinal ETEC infection. Vet. Res. 2009, 40, 40.

[28] Voss, K. A., Riley, R. T., Norred, W. P., Bacon, C. W. et al., An overview of rodent toxicities: liver and kidney effects of fumonisins and Fusarium moniliforme. Environ. Health Perspect. 2001, 109, 259-266.

[29] Broomhead, J. N., Ledoux, D. R., Bermudez, A. J., Rottinghaus, G. E., Chronic effects of fumonisin B-1 in broilers and turkeys fed dietary treatments to market age. Poult. Sci. 2002, 81, 56-61.

[30] Etienne, M., Wache, Y., in: Oswald, I. P., Taranu, I. (Eds.), Mycotoxins in Farm Animals, Research Signpost, Kerala 2008, pgs. 113-130.

[31] Odhav, B., Adam, J. K., Bhoola, K. D., Modulating effects of fumonisin B1 and ochratoxin A on leukocytes and messenger cytokines of the human immune system. Int. Immunopharmacol. 2008, 8, 799-809.

[32] Bergsjo, B., Langseth, W., Nafstad, I., Jansen, J. H., Larsen, H. J. S., The effects of naturally deoxynivalenol-contaminated oats on the clinical condition, blood parameters, performance and carcass composition of growing pigs. Vet. Res. Commun. 1993, 17, 283-294.

[33] Rotter, B. A., Thompson, B. K., Lessard, M., Effects of deoxynivalenol-contaminated diet on performance and blood parameters in growing swine. Can. J. Anim. Sci. 1995, 75, 297-302.

[34] Zielonka, L., Wisniewska, M., Gajecka, M., Obremski, K., Gajecki, M., Influence of low doses of deoxynivalenol on histopathology of selected organs of pigs. Pol. J. Vet. Sci. 2009, 12, 89-95.

[35] Chen, F., Ma, Y. L., Xue, C. Y., Ma, J. Y. et al., The combination of deoxynivalenol and zearalenone at permitted feed concentrations causes serious physiological effects in young pigs. J. Vet. Sci. 2008, 9, 39-44.

[36] Tiemann, U., Brussow, K. P., Kuchenmeister, U., Jonas, L. et al., Influence of diets with cereal grains contaminated by graded levels of two Fusarium toxins on selected enzymatic and histological parameters of liver in gilts. Food Chem. Toxicol. 2006, 44, 1228-1235.

[37] Pinton, P., Nougayrede, J. P., Del Rio, J. C., Moreno, C. et al., The food contaminant deoxynivalenol, decreases intestinal barrier permeability and reduces claudin expression. Toxicol. Appl. Pharmacol. 2009, 237, 41-48.

[38] Marin, D. E., Gouze, M. E., Taranu, I., Oswald, I. P., Fumonisin B1 alters cell cycle progression and interleukin-2 synthesis in swine peripheral blood mononuclear cells. Mol. Nutr. Food Res. 2007, 51, 1406-1412.

[39] Bimczok, D., Doll, S., Rau, H., Goyarts, T. et al., The Fusarium toxin deoxynivalenol disrupts phenotype and function of monocyte-derived dendritic cells in vivo and in vitro. Immunobiology 2007, 212, 655-666.

[40] Wache, Y. J., Hbabi-Haddioui, L., Guzylack-Piriou, L., Belkhelfa, H. et al., The mycotoxin Deoxynivalenol inhibits the cell surface expression of activation markers in human macrophages. Toxicology 2009, 262, 239-244.

[41] Loiseau, N., Debrauwer, L., Sambou, T., Bouhet, S. et al., Fumonisin B-1 exposure and its selective effect on porcine jejunal segment: sphingolipids, glycolipids and transepithelial passage disturbance. Biochem. Pharmacol. 2007, 74, 144-152.

[42] Soriano, J. M., Gonzalez, L., Catala, A. I., Mechanism of action of sphingolipids and their metabolites in the toxicity of fumonisin B1. Prog. Lipid Res. 2005, 44, 345-356.

[43] Furuya, H., Ohkawara, S., Nagashima, K., Asanuma, N., Hino, T., Dietary sphingomyelin alleviates experimental inflammatory bowel disease in mice. Int. J. Vitam. Nutr. Res. 2008, 78, 41-49.

[44] Pinelli, E., Poux, N., Garren, L., Pipy, B. et al., Activation of mitogen-activated protein kinase by fumonisin B-1 stimulates CPLA(2) phosphorylation, the arachidonic acid cascade and cAMP production. Carcinogenesis 1999, 20, 1683-1688.

[45] Dong, C., Davis, R. J., Flavell, R. A., MAP kinases in the immune response. Annu. Rev. Immunol. 2002, 20, 55-72.

[46] Pinton, P., Braicu, C., Nougayrede, J. P., Laffitte, J. et al., Deoxynivalenol impairs porcine intestinal barrier function and decreases the protein expression of claudin- 4 through a mitogen activated protein kinase dependent mechanism. J. Nutr. 2010, 140, 1956-1962. 